tions, including 24-hour ambulant monitoring, revealed only atrial fibrillation. Radiographs of the cervical spine showed spondylolisthesis at the C5 to C6 level. Anterior cervical interbody fusion was performed at this level; the bony changes seen at operation were similar to those described in case 1 . He had no more drop attacks during the last year of his life.

Discussion. We describe two elderly men who had drop attacks and cervical spine instability. In both cases the attacks ceased after limited fusion of the cervical spine. We cannot prove that compression of the vertebral artery was the cause, but this seems likely because of the good results of fusion.

Any fracture or dislocation of the cervical spine above the sixth cervical intervertebral foramen may compromise the vertebral arteries, and relative vascular insufficiency may occur in the basilar artery and its branches as well as in the anterior cervical artery. Both our patients were elderly which may explain why the collateral circulation, from the circle of Willis, was not sufficient to compensate for the diminished flow in the vertebral arteries when flexion of the cervical spine led to subluxation.

In elderly subjects with unexplained drop attacks instability of a degenerate cervical spine should be considered since surgery may prevent these symptoms.

No benefits in any form have been received or will be received from a commercial party related directly or indirectly to the subject of this article.

\section{References}

Jabre A. Subintimal dissection of the vertebral artery in subluxation of the cervical spine. Neurosurgery 1991;29:912-5.

Bousser MG, Hasboun D, Laplane D. Extracranial vertebral artery dissections: a review of 13 cases. Stroke 1987;18:1037-47.

Schneider RC, Crosby EC. Vascular insufficiency of brainstem and spinal cord in spinal trauma. Neurology 1959;9:643-56.

Sheehan S, Bauer RB, Meyer JS. Vertebral artery compression in cervical spondylosis: arteriographic demonstration during live of vertebral artery sufficiency due to rotation and extension of the neck. Neurology (Minneap) $1960 ; 10: 968-86$.

\title{
SMITH-PETERSEN VITALLIUM MOULD ARTHROPLASTY: A 45-YEAR FOLLOW-UP
}

\author{
K. MAHALINGAM, D. REIDY
}

In 1938 Smith-Petersen introduced a vitallium mould arthroplasty using a cup made from cobalt-chrome alloy (Smith-Petersen 1948). This allowed movement between the cup and the bone surfaces of the acetabulum and the femoral head and neck. Problems of cup instability led to the development of a ball-on-stick design by the Judet brothers (Judet and Judet 1950). Despite the early failure of most of these, Hettfleisch and Wissenbach (1994) reported a Judet prosthesis which had survived for 40 years. We now report a Smith-Petersen mould arthroplasty which has been in place for 45 years.

Case report. In November 1994 a 70-year-old woman com-

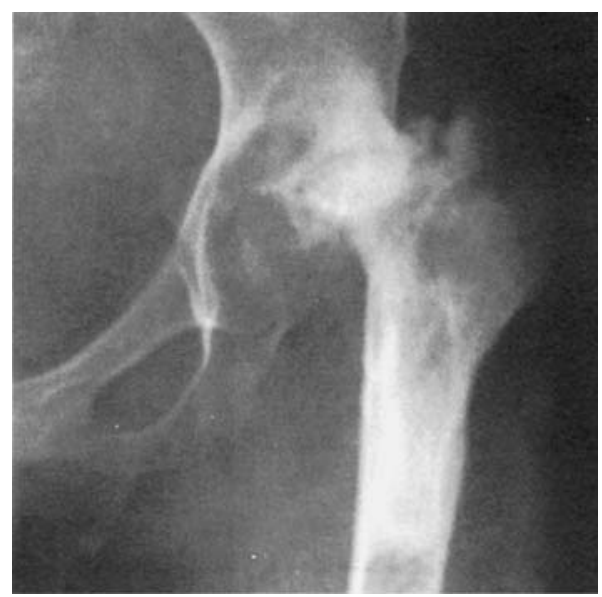

Fig. 1

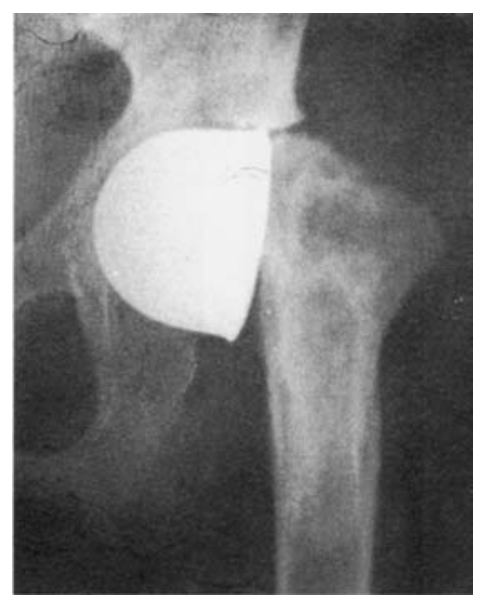

Fig. 2

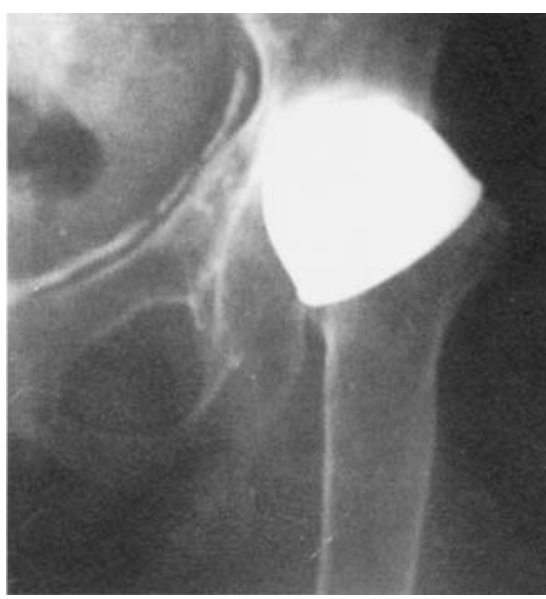

Fig. 3
K. Mahalingam, MB BS, FRCS I, Consultant Orthopaedic Surgeon D. Reidy, MB, BCh, BAO, FRCS I, Orthopaedic Research Registrar Cork University Hospital, Wilton, Cork, Republic of Ireland.

Correspondence to Mr D. Reidy at the Department of Orthopaedic Surgery, Mater Misericordiae Hospital, Eccles Street, Dublin 7, Republic of Ireland.

(C)1996 British Editorial Society of Bone and Joint Surgery 0301-620X/96/3R60 \$2.00

J Bone Joint Surg [Br] 1996;78-B:496-7.

Received 16 February 1995; Accepted 4 May 1995 plained of pain in her left knee after a fall. Radiographs showed an undisplaced fracture of the lateral condyle of the femur, which was treated conservatively. The patient expressed the hope that we would "do as good a job on my knee as Mr Law did on my hip in 1949:. A radiograph of the pelvis showed a mould arthroplasty of her left hip.

In 1932 she had had an operation for congenital dislocation of the hip. By the age of 25, in 1949, she had severe 
pain due to gross degenerative changes (Fig. 1). Mr W. Alexander Law at the London Hospital performed a vitallium mould arthroplasty in October 1949 (Fig. 2). She returned to work after eight months and enjoyed an active lifestyle until her retirement in 1984.

When seen in January 1995 she walked with a limp but did not require a walking aid and was free from pain. There was true shortening of $6 \mathrm{~cm}$ on the left side and a positive Trendelenburg sign. There was no fixed-flexion deformity and she had an excellent range of movement. A radiograph showed settling of the prosthesis with considerable resorption of the neck (Fig. 3).

Discussion. The first mould arthroplasty was made in 1923 from glass and inserted in an ankylosed hip by SmithPetersen at Massachusetts General Hospital. Over the next two decades, a number of different materials were used until vitallium was introduced in 1938. The Smith-Petersen cup arthroplasty was a standard method of hip reconstruction until the advent of total hip replacement (Charnley 1961).

There have been other reports of prostheses with long survival times, but we could find no other record of a satisfactory result at 45 years.

No benefits in any form have been received or will be received from a commercial party related directly or indirectly to the subject of this article.

\section{References}

Charnley J. Arthroplasty of the hip: a new operation. Lancet 1961;i:1129-32.

Hettfleisch J, Wissenbach R. Forty-year survival of a Judet hip prosthesis: a case report. J Bone Joint Surg [Br] 1994;76-B:671-2.

Judet J, Judet R. The use of an artificial femoral head for arthroplasty of the hip joint. J Bone Joint Surg [Br] 1950;32-B:166-73.

Smith-Petersen MN. Evolution of mould arthroplasty of the hip joint. $J$ Bone Joint Surg [Br] 1948;30-B:59-75.

\title{
THE VASCULAR SUPPLY TO BONE IN DISTRACTION OSTEONEOGENESIS: AN EXPERIMENTAL STUDY
}

\author{
R. MOSHEIFF, J. CORDEY, B. A. RAHN, S. M. PERREN, H. STEIN
}

A fundamental requirement of bone healing and reconstitution is an adequate blood supply to the soft-tissue bed surrounding the bone defect. There have been many studies on the effect of the regional blood supply on fracture healing and on the development of delayed union (Brookes 1960; Trueta 1963, 1974; Rhinelander 1968), but in distraction osteoneogenesis the vascular supply to the new bone has not been defined.

We aimed to describe the anatomy of the regional blood supply to the new bone created by distraction.

Materials and methods. We used two adult female Swiss Mountain sheep, aged five and seven years and weighing 59 and $62 \mathrm{~kg}$, respectively. Under general anaesthesia with endotracheal intubation and controlled respiration, a modified circular four-ring fixation frame was mounted on to the left tibia using stainless-steel Kirschner wires $1.6 \mathrm{~mm}$ in diameter. A $2.5 \mathrm{~cm}$ segment of bone was then resected

\footnotetext{
R. Mosheiff, MD

Department of Orthopaedic Surgery, Hadassah Medical Centre, PO Box 1200, Jerusalem, Israel 91120.

J. Cordey, DSc

B. A. Rahn, MD, DMD

S. M. Perren, MD, DSc

AO Research Institute, Calvadelerstrasse, Davos Platz, Switzerland 7270.

H. Stein, MD, DPhil

Department of Orthopaedic Surgery, Rambam Medical Centre, Haaliah

Street, Haifa, Israel 31096.

Correspondence to Dr R. Mosheiff.
}

(C)1996 British Editorial Society of Bone and Joint Surgery

0301-620X/96/3R67 \$2.00

J Bone Joint Surg [Br] 1996;78-B:497-8.

Received 29 August 1995; Accepted 1 November 1995 through two parallel osteotomies with an oscillating saw. The bone ends were brought into contact and the wound closed in layers. After 72 hours mechanical distraction of the bone gap was begun at $0.35 \mathrm{~mm}$ every eight hours, for 28 days. The external fixation frame was left in place for consolidation for seven days.

On day 35, under general anaesthesia and heparinisation, we infused by hand through the femoral artery a $15 \%$ suspension of Micropaque (Laboratoires Nicholas, Gaillard, France) barium sulphate in water containing $1.5 \%$ gelatin (maintained at $37^{\circ} \mathrm{C}$ in a water-bath). The animals were then killed and the blood vessels of the tibia ligated and the left tibia excised. The specimens were fixed in $4 \%$ buffered formalin and cleared by the Spalteholz technique (Spalteholz 1911). The intact transilluminated bones were observed through a stereomicroscope so that the gross external and internal vasculature could be seen.

Results. Around the edges of the bone gap we observed masses of callus composed of rather dense connective tissue with areas of calcification due to membranous ossification. On the posterior surface the callus was in close contact with the muscle bed in which a longitudinal vessel ran in a craniocaudal direction. From it, a major bifurcating branch entered the new bone in the translucent middle plane ('equatorial line') and reached the anterior periosteal border (Fig. 1). Within the gap a plexus of vessels developed (Fig. 2). There were no new independent vessels in the anterior part of the new bone.

Medullary vessels did not cross the osteotomy site. A small number sprouted from the medullary cavity of the distal bone fragment and ran in a cranial direction to supply the distal medullary part of the callus (Fig. 3). 